\title{
CONTROLE ESTRATÉGICO E PROPOSTA DE VALOR NO MODELO DE NEGÓCIO DE OPERADORES LOGÍSTICOS COM SEDE NO BRASIL
}

\section{RESUMO}

O presente artigo objetiva caracterizar a proposta de valor e o controle estratégico utilizado no modelo de negócio das principais Operadores Logísticos (OL) de empresas de logística, sediadas no país. Para tanto, utilizou-se de uma amostra por disponibilidade, conveniência e acessibilidade, dos principais OLs brasileiros. Foram enviados 285 questionários, respondidos 206 e considerados apenas 185 para tratamento estatístico descritivo. Os principais resultados indicam que os OLs pesquisados diferem em suas propostas de valor e controle estratégico em função de seu porte típico. Grandes OLs oferecem pacotes completos de serviços logísticos extras, enquanto médios comprometem-se co serviços, dentro de um grau permissível de terceirizações e pequenos OLs modelam seus negócios apenas pelo que lhes permite sua especialidade. Conclui-se que o modelo de negócio dos OLs sediados no país varia tanto na forma e na natureza, quanto no volume de suas propostas de valor, que se enquadram dentro do conceito de superserviços, serviços por conveniência e serviços por especialidade, respectivamente. O controle estratégico, porém, é diversificado e orienta-se por razões de capacidade racional de suas estruturas, nos OLs de grande e médio portes e por razões de especialidade nos de pequeno porte.

Palavras-chave: Modelo de Negócio; Operador Logístico; Prestador de Serviços Logísticos; Proposta de Valor; Controle Estratégico.

\section{STRATEGIC CONTROL AND VALUE ADDED IN THE BUSINESS MODEL AMONG LOGISTICS OPERATORS SET IN BRAZIL}

\begin{abstract}
This paper aims at characterize the strategic control and value added in busisness model among Logistics Operators (LO) set in Brazil. To do this we use a sample of the logistics enterprises population, set in Brazil, by availability, convenience, and accessibility, among the main Brazilian LOs. We mail 285 questionaires to the selected LOs and received back 185 thoroughly answered, which were statically processed. Main results indicate that LOs surveyed clearly differ regarding value added and strategic control as per their tipical size. Big LOs offer complete extra logistic pack, while middle size LOs compromise with services within a limited outsourced degree of functions and low size LOs cast their business under their own specialties. We may conclude that business model of LOs set in Brazil varies in format and nature as well as in amount of value added, which fit within the concept of superservices, services by convenience and services by specialty, respectively. The strategic control, however, is diversified among LOs and big and middle size LOs use the rationality of their structures to guarantee control, while small LOs use their especialty.
\end{abstract}

Keywords: Business Model; Logistics Operator; Logistics Business Services; Value Added; Strategic Control. 


\section{CONTROL Y PROPUESTA DE VALOR ESTRATÉGICO NO OPERADORES LOGÍSTICOS MODELO DE NEGOCIO CON SEDE EN BRASIL}

\section{RESUMEN}

Este artículo tiene como objetivo caracterizar la propuesta de valor y el control estratégico utilizado en el modelo de negocio de las grandes empresas de logística operadores logísticos (OL), con sede en el país. Por lo tanto, se utilizó una muestra de disponibilidad, comodidad y accesibilidad, los principales OLS brasileños. Se enviaron 285 cuestionarios aplicados a 206 y 185 considerarse únicamente para el análisis estadístico descriptivo. Los principales resultados indican que la OSL encuestados difieren en sus propuestas de valor y el control estratégico debido a su tamaño normal. Grandes OLS ofrecen paquetes completos de servicios logísticos adicionales, mientras que el promedio realizar servicios conjuntos dentro de un grado permisible de la externalización y pequeñas OLS modelo de su negocio sólo por lo que les permite su especialidad. De ello se desprende que el modelo de negocio de OLS con base en el país varía en su forma y en la naturaleza, como el volumen de sus propuestas de valor, que caen dentro del concepto de superserviços, servicios para los servicios de conveniencia y de la especialidad, respectivamente. El control estratégico, sin embargo, es diversa y se guía por razones de capacidad racional de sus estructuras, grandes y medianas OLs y razones de especialidad los pequeños.

Palabras clave: Modelo de Negocios; Operador de Logística; Proveedor de Servicios de Logística; Propuesta de Valor; El Control Estratégico.

Clébia Ciupak Ferreira ${ }^{1}$

Leonel Cezar Rodrigues ${ }^{2}$ Marcos Antonio Maia de Oliveira ${ }^{3}$ Valeria Riscarolli ${ }^{4}$

\footnotetext{
${ }^{1}$ Doutoranda do Curso de Administração da Universidade Nove de Julho - UNINOVE. Professora da Universidade Federal de Mato Grosso - UFMT. Brasil. E-mail: clebia.ciupak@gmail.com

${ }^{2}$ Doutor em Administração Universitária pela Vanderbilt University, Estados Unidos. Professor do Programa de pósGraduação em Administração da Universidade Nove de Julho - UNINOVE. Brasil. E-mail: leonel@uni9.pro.br

${ }^{3}$ Doutor em Administração pela Universidade Nove de Julho - UNINOVE. Professor do Centro Paula Souza - FATEC. Brasil. E-mail: marcos.maia@ fatec.sp.gov.br

${ }^{4}$ Doutora em Administração pela Universidade de São Paulo - USP. Professora da Faculdade das Américas - FAM. Brasil. E-mail: riscarollival@ hotmail.com
} 


\section{INTRODUÇÃO}

Nos últimos anos, a evolução das práticas empresariais tem levado as empresas de uma forma geral a considerar a logística como condicionante de sua eficácia operacional. Isto porque o raio de ação da mesma se estende a todas as operações da organização, envolvendo desde o suprimento de matéria-prima, entrega do produto final, até o gerenciamento dos espaços. Nesse âmbito, a função logística, passa a desempenhar um novo papel: o de centralização na distribuição e adequação dos espaços físicos da empresa e na criação de valor, otimizando recursos e capacidades para movimentar os produtos, armazená-los e garantir sua entrega aos respectivos destinos, no tempo previsto e a um custo competitivo.

A logística tem passado do status tradicional de dependência passiva do negócio de outras organizações, representada pela simples execução da mobilização de materiais de uma organização para outra, para um status de ação estratégica, com características únicas de competição. A geração de valor em suas atividades, passa agora a ser percebida como um negócio que deve competir por espaços mercadológicos mais lucrativos e mais farto em opções economicas. Esse processo centraliza-se principalmente em alguns aspectos da ação logística, evolvendo, por exemplo, necessidades de serviço ao cliente, lead time dos processos logísticos, custo, valor agregado, opções de fonte de produto e análises de trade offs (Christopher, 2001). Tais elementos precisam ser perfeitamente ajustados para cada busca, transporte e entrega de produto, objeto da ação logística.

Pode-se imaginar, a importância das operações logísticas para os negócios. Pela natureza de seus processos, a logística pode determinar a eficácia operacional e influenciar decisivamente, a capacidade competitiva da empresa. Sendo a logística um instrumento tão importante para as empresas nada mais justificável do que uma análise mais detalhada de como as empresas de logística estão adequando seus negócios para melhor competir em seus segmentos.

A empresas prestadoras de serviços logísticos, evoluíram ao longo do tempo, muito mais em função da alteração do tipo de demanda dos serviços logísticos. Originalmente, as atividades logísticas eram incorporadas pelas próprias empresas, geradoras de produtos. A crescente competição no mundo e a consequente sofisticação dos negócios, em especial a partir da década de 1980, a necessidade de agilidade empresarial e de abaixamento de custos operacionais fizeram com que as atividades não centrais aos negócios fossem terceirizadas de forma enfática. Assim, as atividades logísticas foram terceirizadas, dando de fato espaço para que tais atividades fundamentassem um segmento econômico importante e necessário no contexto empresarial. As empresas de serviços de logística foram, então, sofisticando a forma e tipo de oferta de seus serviços, de tal maneira que as mais arrojadas começaram a gerenciar o conjunto de serviços oferecidos, não apenas executá-los sob demanda. Nascem, desta forma, os Operadores Logísticos, que se envolvem não apenas com transporte, como os prestadores logísticos tradicionais, mas com a gestão da armazenagem e agregados que aumentam o valor dos serviços logísticos, como aponta Lieb (1996). Fleury e Ribeiro (2001) inclusive detalham uma lista específica de serviços distintivos, típicos dos Operadores Logísticos.

Operadores Logísticos, portanto, são empresas de transporte, armazenagem e movimentação de cargas que olham tais atividades como seu campo dos negócios. Sua visão não é apenas passiva, no sentido de reagir a demandas de transporte, mas antes ativa, oferecendo serviços e tornando a logística um verdadeiro campo de atividade de transação sócioeconômica. Por essa razão, os OL's requerem Modelos de Negócio adaptados à natureza das atividades que idealizam como seu negócio, de forma a permitir maiores ganhos de produtividade e de qualidade nos serviços prestados. Um modelo de negócio descreve a estrutura dos fluxos de produtos/serviços e informações, bem como o respectivo papel dos participantes na estrutura da cadeia de valor que deve ser ou que esteja sendo utilizada para a sua adequada execução (Applegate, 2000).

Desta forma, neste trabalho, considera-se apenas os Operadores Logísticos (OL), como as empresas de logística selecionadas para responderem à pesquisa, por entender-se que são essas empresas que apropriam tais atividades como seus negócios. Sua atitude pró-ativa em relação à logística, requer delas formatos transacionais otimizados e mais perfeitamente adequados a seus ambientes operacionais. É esse tipo de empresa que interessa estudar no contexto deste trabalho.

Modelos de Negócios têm diferentes abordagens, distintos elementos centrais e diversas verdades embasadoras, dependendo de seu foco econômico. Não constituem paradigmas com solução única. Ora assentam-se sobre elementos estruturais de eficácia de suas operações, ora assentam-se sobre fatores estratégicos, que determinam como o negócio precisa ser executado. Dos vários modelos de negócio existentes na literatura especializada, o modelo de Bovet e Martha (2001) parece ser o adequado aos objetivos dessa pesquisa. O Modelo está concebido em cinco dimensões - proposta de valor; abrangência; fontes de lucratividade; controle estratégico; e execução. Por ter sua origem conceptiva nos processos logísticos, foi escolhido como referência para 
verificação do comportamento dos negócios dos Operadores Logísticos sediados no Brasil, objeto dessa pesquisa.

Como parece lógico, há empresas que valorizam determinadas dimensões mais do que outras. Assim, procedeu-se a um levantamento rápido entre os OL, previamente à pesquisa, visando determinar seu foco de interesse ou valorização prioritária em seus negócios. Mais de dois terços dos respondentes deste levantamento preliminar, após certificarem-se do significado das dimensões, apontaram a proposta de valor e o controle estratégico como as determinantes para o sucesso de seus negócios. Assim, neste trabalho, focou-se somente nessas duas dimensões, na tentativa de examinar como estão orientados os modelos de negócio dos principais OL sediado no Brasil.

Considerando-se que a categoria dos OL se distingue das categorias de empresas de agenciamento de cargas e transportadoras, por definição da própria ABML (1999), como referido acima e por serem os OL empresas mais bem estruturadas e proativas na oferta de seus serviços, é razoável imaginar como têm os OL construído seus modelos de negócios, em relação à proposta de valor e ao controle estratégico? Para responder esta questão, determinou-se como objetivo deste trabalho caracterizar a Proposta de valor e o Controle Estratégico utilizados nos modelos de negócio das principais OL atuantes no Brasil.

\section{ANTECEDENTES TEÓRICOS}

Apresenta-se, na sequência, os principais pilares teóricos que funadamentaram esta pesquisa.

\subsection{Provedores de Serviços Logísticos}

Em razão do aumento da importância da logística nas empresas como fonte de vantagem competitiva, observa-se a sua evolução que passa a abranger funções que antes eram conduzidas de forma fragmentada (atividades de transporte $\mathrm{e}$ armazenagem) começaram a ser gerenciadas de forma integrada. Desse modo, seus componentes fundamentais, os fluxos de informações e financeiros correspondentes, estenderam seu âmbito de atuação para a integração com fornecedores, canais de distribuição e clientes.

Logística como método de operação, era circunscrita à solução das necessidades de mobilização militar (transporte e organização de suprimentos). A mobilização e organização de materiais nas organizações sempre teve um papel secundário, já que era vista como uma atividade paralela a outras atividades responsáveis pelo caminho crítico determinante do desempenho das organizações. Mais recentemente, porém, com o conceito de "cadeia de valor" (Porter, 1998), em que a combinação de atividades secundárias com atividades primárias passou a determinar margens de lucro operacionais, a logística tem assumido um papel mais estratégico. Cada elemento de custo, ganhos de tempos, organização e eficiência de mobilização começaram a ter peso no contexto da produtividade, custos e respectivas margens, permitindo uma política mais eficiente de precificação.

O aumento da pressão competitiva sobre as empresas, nas últimas décadas, fez crescer, em importância, a função do gerenciamento logístico dentro das empresas. Ao mesmo tempo, um número de fatores, em especial a terceirização gradativa das atividades primárias tem aumentado a complexidade de seu gerenciamento. Isso tem levado as empresas a terceirizar suas atividades logísticas, o que de fato, fez desabrochar o aparecimento da indústria de serviços logísticos.

Para as empresas demandantes, a terceirização das atividades logísticas esteve associada à redução de custos. Para as empresas de logística, no entanto, simplesmente responder à demanda é desestimulante. Neste segmento econômico de serviços, percebe-se um enfoque mais amplo na relação entre as partes (demandantelogística), convergindo, cada vez mais, para objetivos estratégicos de negócios, como: ampliação de mercado, melhoria no nível de serviço e na flexibilidade para melhor atender às preferências do consumidor (Skjoett-Larsen, 2000).

Copacino (1998) aponta o crescente nível de sofisticação exigido para implementar efetivamente os programas de logística e o gerenciamento da cadeia de abastecimento são fatores estimuladores do crescimento do segmento de empresas de logística. O crescimento desses empreendimentos deve-se, adicionalmente, ao crescente com foco na globalização, no crescimento do e-commerce e na popularização dos requisitos tecnológicos.

Com o reconhecimento de que a logística é uma fonte de vantagem competitiva para as empresas demandantes, houve maior estímulo à formação do mercado dos prestadores de serviços logísticos e com isso um rápido crescimento e diversificação na prestação de tais serviços (Dornier et al., 2000). A evolução, em amplitude e especialização, dos serviços logísticos fez surgir, mais recentemente, além dos Operadores Logísticos, ou Third Party Logistics, os Integradores Logísticos, também são reconhecidos como Fourth Party Logistics.

A crescente complexidade do gerenciamento logístico com a explosão da tecnologia de informação e necessidade de maior integração da cadeia de suprimentos, criou um campo fértil para Integradores Logísticos. De fato, à medida que a tecnologia de informação permite a horizontalização dos negócios, tais facilidades foram 
rapidamente assimiladas por algumas empresas operantes em logística. O Integrador reúne e gerencia os recursos, capacidades e tecnologias de que é detentor com as dos outros prestadores de serviço, para oferecer uma solução ampla e completa na cadeia de suprimento (Bade e Müller, 1999; Skjoett-Larsen, 2000). Assim, um Integrador, na realidade gerencia seu negócio apenas, sem dispor necessariamente de todos os meios de transporte e armazenagem que eventualmente um Operador Logístico dispõe. Mas como integra, possui o seu negócio em estrutura de nebulosa (Rodrigues, 2006), comandando como empresa referência todos os processos de sua atividade econômica.

Em seu segmento, um Integrador Logístico é visto como um prestador de serviço que participa da coordenação da cadeia de suprimento ao invés de participar de suas operações (Hoeke e Chon, 2001). É baseado essencialmente em informação e focado em nãoativos pois coordena os vários participantes ou executantes das atividades logísticas para cumprir as tarefas específicas.

Como possui informação sobre todo o funcionamento e perfil dos participantes, pode oferecer aos clientes alternativas completas de solução mais personalizadas. De fato, o Integrador surgiu em função da demanda da clientela por serviços logísticos, que clamavam por soluções completas de gerenciamento da cadeia de suprimento com serviços adicionais não existentes ou não disponíveis no portfolio de serviços oferecidos pelos participantes individuais.

Além das atividades de gerenciamento direto em níveis estratégico, tático e operacional da cadeia de suprimento e da coordenação e integração de conjuntos de prestadores de serviços logísticos responsáveis pela execução de serviços logísticos específicos, os Integradores também se ocupam com a Reengenharia dos processos da cadeia (Cottrill, 2000; Hoffmann, 2000). Desta forma, Integradores garantem a maior eficácia dos processos logísticos no contexto das atividades logísticas e seu alinhamento com as estratégias de oferta dos serviços, de maneira a servir mais eficientemente seus clientes.
Pode-se imaginar, contudo, que a maioria dos serviços logísticos não cai dentro do conceito de pacotes integrados. Ao contrário, a maior parte desses serviços são mais limitados e requerem apenas pequenas integrações ou subsequenciamentos. Adicionalmente, por serem mais completos, os pacotes de serviços logísticos integrados por várias empresas de logística tendem sempre a custar mais caro. A diferença entre um Integrador e um Operador Logístico está nos graus de utilização da tecnologia de informação e na amplitude da subcontratação. Ao basear seu negócio totalmente nas informações providas por um robusto sistema de informações, os Integradores podem oferecer o que há de melhor em serviços e tecnologia logística, garantido a plena satisfação de necessidades específicas a cada cliente.

Apesar de atrativos, os Integradores possuem um segmento mercadológico menos amplo do que o oferecido pelos Operadores Logísticos. Na realidade, Operadores Logísticos também integram, apenas que com menor amplitude.

Caracteristicamente, a terceirização em logística começou a ser utilizada na década de 80 como sinônimo de "subcontratação de elementos do processo logístico" (Fleury, 2001). Naquele período, a execução de duas ou mais atividades logísticas, para serem realizadas de forma coordenada, passou a ser mais e mais freqüente, de tal forma que a terceirização (third party logistics) foi associada a empresas com capacidade de fornecer mais de um tipo de serviço logístico de forma integrada (Sink et al., 1996; Berglund e Peters, 2000). Estas empresas são conhecidas como Operadores Logísticos. Laarhoven et al. (2000) insistem que a caracterização dos Operadores passa por capacidade de gerenciamento de cargas, gerenciamento de projetos e cooperação entre demandante, Operador e outros serviços especializados, para distingui-lo de um prestador de serviços logísticos simples. No Quadro 1, são apresentadas as diferenças entre prestadores de serviços logísticos tradicionais e operadores logísticos do tipo 3PLs. 
Quadro 1 - Diferenças entre prestadores de serviços logísticos tradicionais e operadores logísticos.

\begin{tabular}{|c|c|c|}
\hline SERVIÇOS & $\begin{array}{c}\text { PRESTADORES DE SERVIÇOS } \\
\text { TRADICIONAIS }\end{array}$ & SOB MEDIDA (PERSONALIZADOS) \\
\hline $\begin{array}{l}\text { Quantidade de } \\
\text { atividades ofertada }\end{array}$ & $\begin{array}{l}\text { Tente a concentrar numa única } \\
\text { atividade logística: transporte ou } \\
\text { estoque, ou armazenagem }\end{array}$ & $\begin{array}{l}\text { Oferece múltiplas atividades logísticas de } \\
\text { forma integrada: transporte, estoque, } \\
\text { armazenagem }\end{array}$ \\
\hline $\begin{array}{l}\text { Objetivo da } \\
\text { empresa } \\
\text { contratante }\end{array}$ & $\begin{array}{l}\text { Minimização do custo específico da } \\
\text { atividade contratada }\end{array}$ & $\begin{array}{l}\text { Redução dos } \\
\text { melhorar os } \\
\text { flos totais } \\
\text { flexibilidade }\end{array}$ \\
\hline $\begin{array}{l}\text { Duração do } \\
\text { contrato de serviço }\end{array}$ & Curto a médio prazos ( 6 meses a 1 ano) & Longo prazo (5 a 10 anos) \\
\hline Know-how & $\begin{array}{l}\text { Kimitado e especializado (transporte, } \\
\text { armazenagem, etc) }\end{array}$ & $\begin{array}{l}\text { Possui ampla capacitação de } \text { análise e } \\
\text { planejamento logístico, assim como de } \\
\text { operação }\end{array}$ \\
\hline $\begin{array}{l}\text { Duração das } \\
\text { negociações }\end{array}$ & $\begin{array}{l}\text { Tendem a ser rápidas (semanas) e em } \\
\text { nível operacional }\end{array}$ & $\begin{array}{l}\text { Tender a ser longas (meses) e em alto nível } \\
\text { gerencial }\end{array}$ \\
\hline
\end{tabular}

Fonte: FLEURY, P. F. Vantagens Competitivas e Estratégicas no Uso de OperadoresLogísticos. Centro de Estudos em Logística - COPPEAD - UFRJ, 2001.

Este trabalho envolveu todos os três tipos de prestadores de serviços logísticos, os Integradores, Operadores e Prestadores de serviços logísticos tradicionais. Contudo, para simplificação, chamaremos todas as empresas de operadores logísticos, distinguindo-os em grandes, médios e pequenos.

\subsection{Modelo de Negócio}

Para Gomes e Ribeiro (2004), um modelo de negócios define o valor que uma organização oferece aos seus vários clientes, caracterizando a capacidade e os parceiros necessários para criar, fazer marketing e fornecer esses valores bem como ampliar suas relações com o objetivo de gerar fluxos de rendimentos sustentáveis e lucrativos. Ainda segundo esse autor, as empresas antes de se lançar no mercado, ao investir na definição dos seus modelos de negócios certamente obterão, entre outros fatores, redução de custos, maior rapidez na exploração de novas oportunidades, redução dos riscos de investimento de capital e flexibilidade no alcance de seus objetivos.

Hagel III (2003) propõe uma evolução no formato dos negócios, com base na interconectividade das empresas. Desaparecem assim as cadeias físicas e os negócios tornam-se cada vez mais cibernéticos. As empresas deixam de se verticalizar e passam a horizontalizar-se, transferindo seus processos a outras empresas que passam a desenvolver especialidades para a rede conectada, de tal maneira que as empresas passam a orquestrar um conjunto de outras empresas que fazem parte ou viabilizam seu negócio, que ele chama de nebulosa de parceiros. Para chegar a orquestrar este conjunto, as empresas passam por três estágios: Redução de custos; Foco na Especialização; Foco no Crescimento alavancado. Na visão de Hagel (2003), a implicação do novo modelo de negócio é uma nova estrutura empresarial, horizontalizando o respectivo modelo de negócio.

Bovet e Martha (2001) propõem um modelo de negócios que utiliza os conceitos da cadeia de suprimento digital para obter a maior satisfação do cliente e a lucratividade da empresa. Está assentado sobre cinco premissas: Proposta de valor; abrangência; origem dos lucros; controle estratégico e execução. O modelo é um sistema flexível, alinhando e conduzindo pelas escolhas dos clientes. Cada premissa é caracterizada por um conjunto de atributos de valor que aumentam a reciprocidade entre clientes, a empresa e fornecedores, cujo centro de gravidade é o cliente e seus interesses. A Figura 1 abaixo mostra a estrutura do modelo.

Pelo interesse do modelo para este trabalho, foca-se aqui apenas na proposta de valor e controle estratégico. A primeira envolve três características essenciais, superserviços, conveniência e personalização. Já o controle estratégico envolve outros atributos intangíveis, relacionados à marca, às relações com clientes e fornecedores e ao desenho de oferta de seus serviços e/ou produtos. 


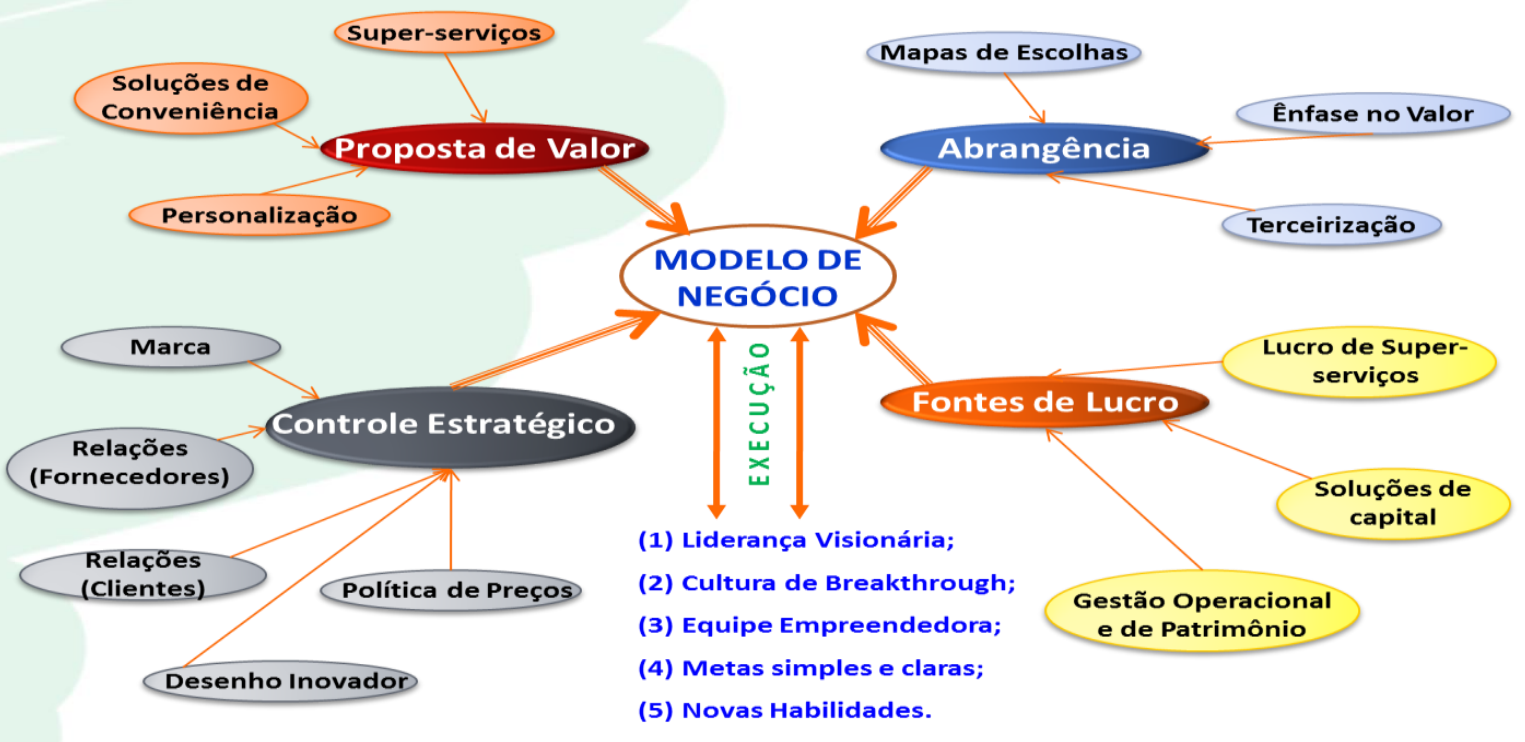

Figura 1- Modelo de Negócio de Redes de Valor.

Fonte: Adaptado de Bovet e Martha, (2001).

Este sistema, segundo os autores, está orientado pela demanda, focado na criação de uma rede de valor, isto é, para a geração de valor para os clientes, para a empresa e para os fornecedores. A disposição dos elementos e sua operacionalização permite à empresa de um lado criar valor de forma personalizada para seus clientes e, de outro, capturar o valor gerado na forma de maior satisfação e fidelização de seus clientes e fornecedores.

\section{METODOLOGIA}

O Modelo de Reconfiguração de Negócio, conforme a Figura 1, apresenta um escopo além do autodiagnóstico de criação, pois possibilita fornecer um conhecimento sobre as oportunidades que o conceito das redes de valor oferece às organizações. Permite ainda revelar áreas onde poderão ocorrer análises mais detalhadas, objetivando um diagnóstico completo de uma rede de valor, ensejando uma possível adequação no modelo de negócio das empresas/operadores pesquisadas.

As empresas, objeto deste estudo, pertencem ao setor de prestação de serviços logísticos, com sede na Região da Grande São Paulo. São empresas consideradas de grande, médio porte e pequeno porte e disputam fatias de mercado, ora por liderança em custo, ora por diferenciação, na área de serviços logísticos.

Buscando entender as características das empresas, essa pesquisa envolveu uma amostragem de 285 empresas na proporção de $20 \%$ x $40 \%$ x $40 \%$, entre grandes, médias e pequenas empresas. Obteve-se um retorno de 206 questionários retornados, dos quais foram utilizados 185 questionários respondidos completamente, inutilizando-se 21, por incompletude de respostas. O questionário com 16 perguntas, perscrutou os valores agregados (serviços oferecidos como diferenciais), os segmentos mais buscados e a logística dedicada por cada respondente, como lógica para avaliação das propostas de valor e controle estratégico realizado pelos OL.

Para realização deste trabalho, os sujeitos sociais selecionados foram os gestores e colaboradores da área operacional das empresas selecionadas. O tamanho da amostra foi dimensionado de acordo com os critérios de conceito (a empresa precisa possuir as características de OL para fazer parte da amostra) e tamanho (grandes, médios e pequenos), dentro da lógica de amostragem proposta por Mattar (1999). Os dados foram coletados em setembro e outubro de 2011, que se trata de época com volume de serviços regular, tendo em vista as particularidades dos serviços prestados.

Nessa coleta de dados e informações, foram observadas as normas do Código Internacional de Pesquisas Sociais e de Mercado, da European Society for Opinion and Marketing Research ESOMAR, de forma voluntária, respeitando o direito de privacidade e a garantia de que as informações prestadas pelo entrevistado não terão outra finalidade (ESOMAR, 2010). Quando da aplicação dos instrumentos, utilizou-se o método de comunicação não disfarçada, enfatizando-se ao respondente a relevância de sua participação na pesquisa.

O método de pesquisa adotado foi o survey (pesquisa de campo) pois é o que busca informação diretamente com um grupo de interesse a respeito dos dados que se deseja obter. Segundo Santos 
(2001), “trata-se de um procedimento útil especialmente em pesquisas exploratórias e descritivas". Este método de pesquisa apresenta, dentre as principais vantagens, o conhecimento direto da realidade; a economia e rapidez e a possibilidade de análise estatística dos dados colhidos. A pesquisa teve o objetivo de levantar informações referentes a atuação dos operadores logísticos e caracterizar o Modelo de Negócio dessas empresas, atuantes no Brasil, usando o Modelo de Negócio proposto por Bovet e Martha (2001), como parâmetro orientador.

Os questionários foram aplicados diretamente aos gestores dos prestadores de serviços logísticos, na tentativa de facilitar o acesso aos mesmos e obter um retorno maior de questionários respondidos. A composição do questionário apresentou dois compnentes, dos cinco analisados por Bovet e Martha (2001), sendo Proposta de Valor, o que a empresa vai oferecer aos clientes potencialmente lucrativos e Controle Estratégico, como a empresa protege sua fonte de lucro por meio de vantagens competitivas sustentáveis.

\section{RESULTADOS E DISCUSSÕES}

O universo de empresas que atuam nesse setor, segundo a Associação Nacional de Transporte de Carga e Logística - ANTC \& Logística (2015), congrega além das empresas diretamente associadas (por volta de 3500 ), mais de 50 entidades patronais (federações, Sindicatos e Associações especializadas). A Associação representa cerca de 10.500 empresas que operam uma frota superior a 1,5 milhão caminhões e sustentam um contingente de cerca de 1 milhão de postos de trabalho (ANTC \& Logística, 2015).

Buscando entender as características das empresas pesquisadas, a análise dos dados foi dividida em 3 grupos observando as características funcionais e estruturais das mesmas, numa proporção de $20 \%$ × $40 \%$ × $40 \%$, entre grandes, médios e pequenos OL. O questionário possui 16 perguntas, perscrutando genericamente os valores agregados (serviços oferecidos como diferenciais), segmentos mais buscados e logística dedicada.

As perguntas varrem as principais características, ou funcionalidades críticas, que definem o perfil de um modelo de negócio, fundamentalmente voltadas para duas dimensões: a proposta de valor e o controle estratégico. Para melhor clareza e eficiência da análise das respostas, dividiu-se as amostras dos respondentes em 3 blocos distintos: Grandes Operadores Logísticos, Médios Operadores Logísticos e Pequenos Operadores Logísticos.

\subsection{Grandes Operadores Logísticos (Grupo 1)}

Grandes Operadores Logísticos são PSL's atuantes em diversos setores, tais como: automotivo, guarda de documentos, transporte de valores, produtos alimentícios, carga fracionada, produtos multitemperaturas e sensíveis e carga expressa, todos com abrangência nacional. $\mathrm{O}$ portfólio dos serviços oferecidos é abrangente em razão da necessidade de capacitação funcional para atender de forma completa o cliente. Possuem estrutura de acompanhamento de todo processo logístico do cliente (do fornecedor à pós-venda) e nos casos de clientes que deixam de solicitar serviços, contatam o mesmo buscando entender os motivos e adequandose a requisitos específicos exigíveis por esses clientes. Esses Operadores destacam-se por oferecerem serviços personalizados para muitos clientes, com rapidez. Como oferecem serviços via $w e b$, permitem solicitação de serviços a qualquer hora, pelos seus clientes, além de oferecerem grande flexibilidade nos processos logísticos.

\subsection{Médios Operadores Logísticos (Grupo 2)}

Estão elencados nesse grupo PSL's atuantes em diversos setores, tais como: entregas e encomendas expressas, comércio eletrônico, cargas fracionadas, cargas secas em geral. Dos serviços oferecidos pelos PSL desse grupo, a maioria atua no comércio eletrônico, com entregas rápidas/expressas. O comércio eletrônico, no Brasil, segundo dados da empresa e-bit Informação (Empresa de Inteligência de Comércio Eletrônico) segue os passos do comércio eletrônico americano, que funciona como referência espelho para o setor (Wilson, Delnaey \& Delaney, 2015). Segundo informações dessa empresa de e-commerce, 2006 foi o ano em que o setor registrou a maior taxa de crescimento: $76 \%$, sendo que nos anos subsequentes, o desempenho tem se mantido em escala ascendente, ainda que em menor grau, mas comprovando que o brasileiro está perdendo o medo de usar esse canal e cada vez mais se deixa seduzir não apenas pela facilidade e comodidade, mas pela variedade das formas de pagamento e possibilidade de parcelamento, dentre outras opções.

\subsection{Pequenos Operadores Logísticos (Grupo 3)}

Grande parte dos OLs pesquisados nesse Grupo são Operadores que oferecem soluções direcionadas a clientes específicos, em razão da diversidade de tipo de produto/mercadoria transportada. Envolvem desde cargas excedentes em determinados clientes, movimentação de containers, transportes de maquinários para a construção civil, a carga lotação (ocupam a totalidade da capacidade do veículo), remoções industriais, fazendo que em alguns casos, se especializem em um desses seguimentos. Integram também esse Grupo, 
operadores que prestam serviços para grandes redes de varejo de materiais para construção, reforma e decoração, oferecendo transportes customizados em razão das particularidades dos serviços e sazonalidade. Os resultados das respostas envolvendo o comportamento da amostra total estão comentados seguindo os três grandes tópicos de pesquisa: A - Serviços oferecidos, B - Proposta de serviços específicos e C - Logística dedicada.

\subsection{Serviços oferecidos como diferencial aos clientes}

Avalia-se aqui os diferentes serviços e formas de oferta dos mesmos à clientela dos OL pesquisados.

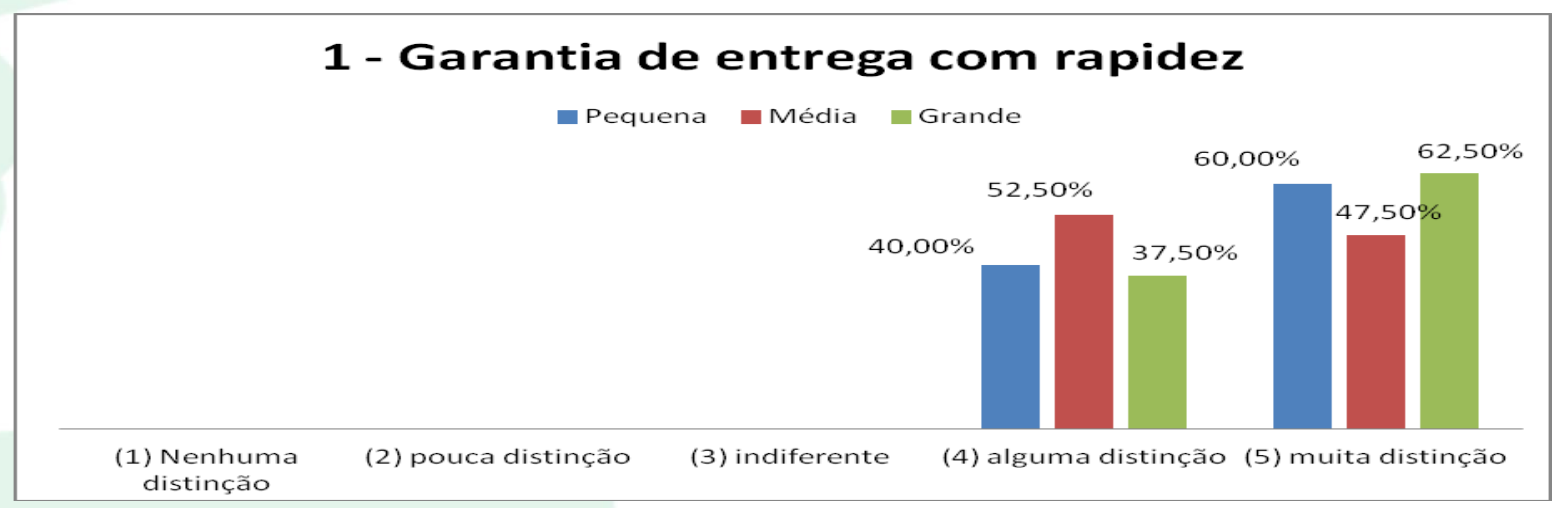

Gráfico 1 - Garantia de entrega com rapidez

Entre os três grupos de operadores $a$ garantia de entrega com rapidez tende a ser percebida pelos dois grupos extremos, pequenos e grandes operadores, como elemento mais distintivo em seus respectivos segmentos. Para eles, entregar com rapidez é importante como mecanismo competitivo por fazê-los distinguirem-se dos concorrentes.

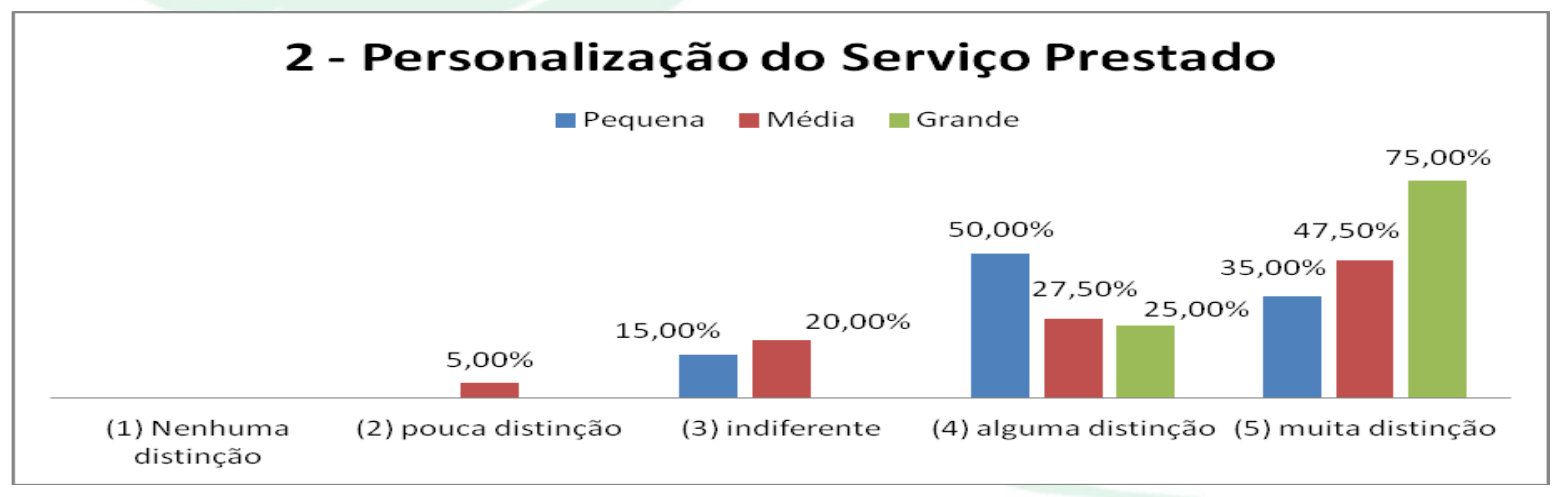

Gráfico 2 - Personalização do Serviço Prestado

A personalização dos serviços prestados tem distintas interpretações de importância no contexto dos processos de negócio dos três grupos analisados. Pequenos operadores tendem a ver a personalização como elemento de alguma distinção, enquanto os operadores médios e grandes tendem a vê-la como muita distinção. Isto significa que, de fato, somente para grandes operadores a personalização é uma forma de distinção de seu negócio. Apesar de quase $50 \%$ dos respondentes dos operadores médios considerarem importante a personalização, ainda 1/4 deles simplesmente é indiferente a ela. 


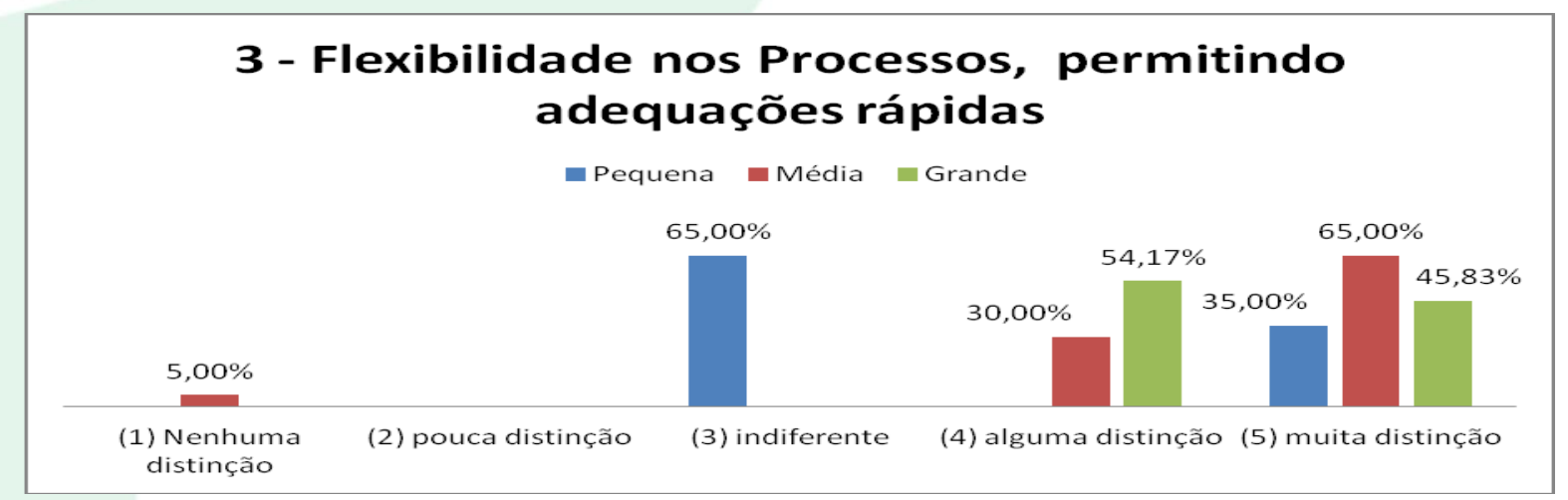

Gráfico 3 - Flexibilidade nos processos

Outro elemento importante para a caracterização do modelo de negócio dos prestadores logísticos refere-se à flexibilização dos processos, entendida como uma alternativa para melhorar o desempenho de entrega dos serviços. As respostas mostram comportamentos bastante distintos. Pequenos operadores mostram-se indiferentes à flexibilização, enquanto grandes operadores, em sua maioria, percebem a flexibilização como um instrumento de alguma distinção. No entanto, médios operadores acreditam fortemente na flexibilização dos processos. Uma razão explicativa pode estar possivelmente no fato de que médios operadores dependem da flexibilização como forma de complementar seus serviços, ao passo que pequenos, por oferecerem somente uma forma de entrega dos serviços e grandes operadores, por oferecerem um portfolio completo, não percebem a necessidade de flexibilização.

\subsection{Conhecimento do Perfil dos Clientes}

O conhecimento do perfil do cliente potencial com o objetivo de oferecer personalização de serviços mostrou uma diversificação nos três Grupos de OL aqui pesquisados.

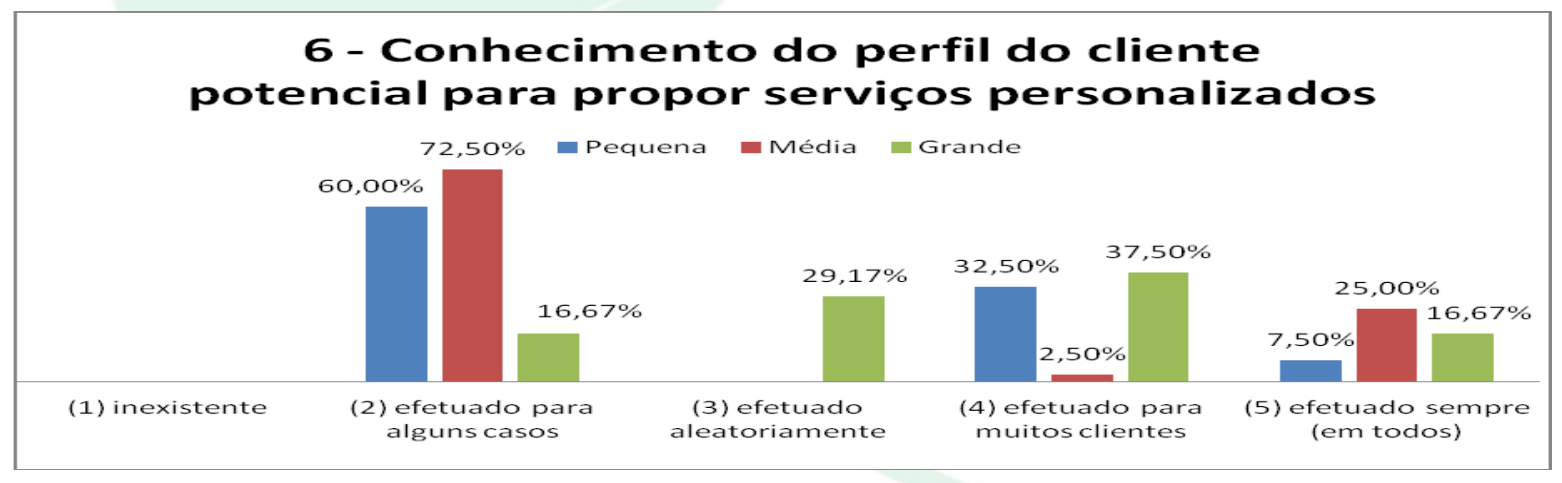

Gráfico 4 - Conhecimento do perfil do cliente

O conhecimento prévio do perfil do cliente para propor serviços personalizados é de interesse apenas em alguns casos para os operadores pequenos e médios, indicando uma gestão do negócio, aparentemente mais intuitiva do que científica ou baseada em informação. Os grandes operadores, entretanto, parecem considerar o cliente per se, antes de descartar o esforço. Assim, para os grandes operadores, a pesquisa mostra ser importante conhecer o perfil do cliente, antes de propor-lhe os serviços personalizados.

\subsection{Liberdade de escolha}

Quando serviços adicionais requerem sua terceirização pelos OL, é necessária a permissão para a utilização do parceiro/prestador do serviço logístico, já que a responsabilidade passa a ser deste. Dessa forma, no Grupo 1 observa-se que $65 \%$ dos OLs utilizam-se desse recurso quando o serviço estiver fora de sua especialidade. No Grupo 2, a movimentação das cargas é de inteira responsabilidade do OL e dessa forma, mesmo 
usando parceiro, não se faz necessária a prévia autorização de outro prestador de serviço para atender à demanda. No Grupo 3, dos grandes OLs, a pemissao se dá não por transferência de responsabilidade, como no caso do Grupo 1 (Pequenos OL), mas por flexibilização de seu portfólio de serviços (Gráfico 5).

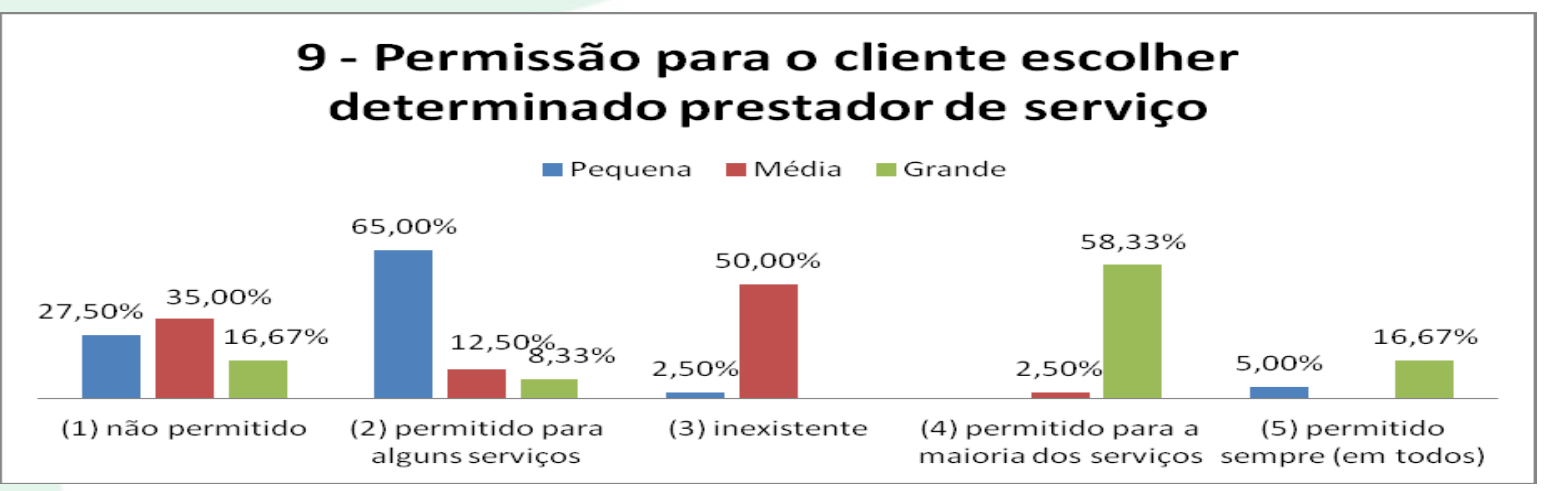

Gráfico 5 - Escolha de prestador de serviço

Além dos itens discutidos acima, verificou-se a preocupação dos OL em relação à melhoria de seus serviços. Apesar de aparentemente óbvio, a preocupação com a melhoria de seus serviços, demonstra indiretamente sua atenção com confiança e aceitação de sua marca no mercado.

\subsection{Busca pela Melhoria dos Servicos e Soluções}

A preocupação dos OL's em relação à busca permanente da melhoria dos serviços/soluções parece ser unânime para os Grupos 2 e 3. Para o Grupo 1, dos Pequenos OLs, para 67,5\% dos integrantes desse grupo. Vários são os motivos que fazem com que os OL's melhorias em seus serviços. Sob o ponto de vista mercadológico, possivelmente o esforço pela melhoria constante se deve à busca por fidelização de seus clientes.

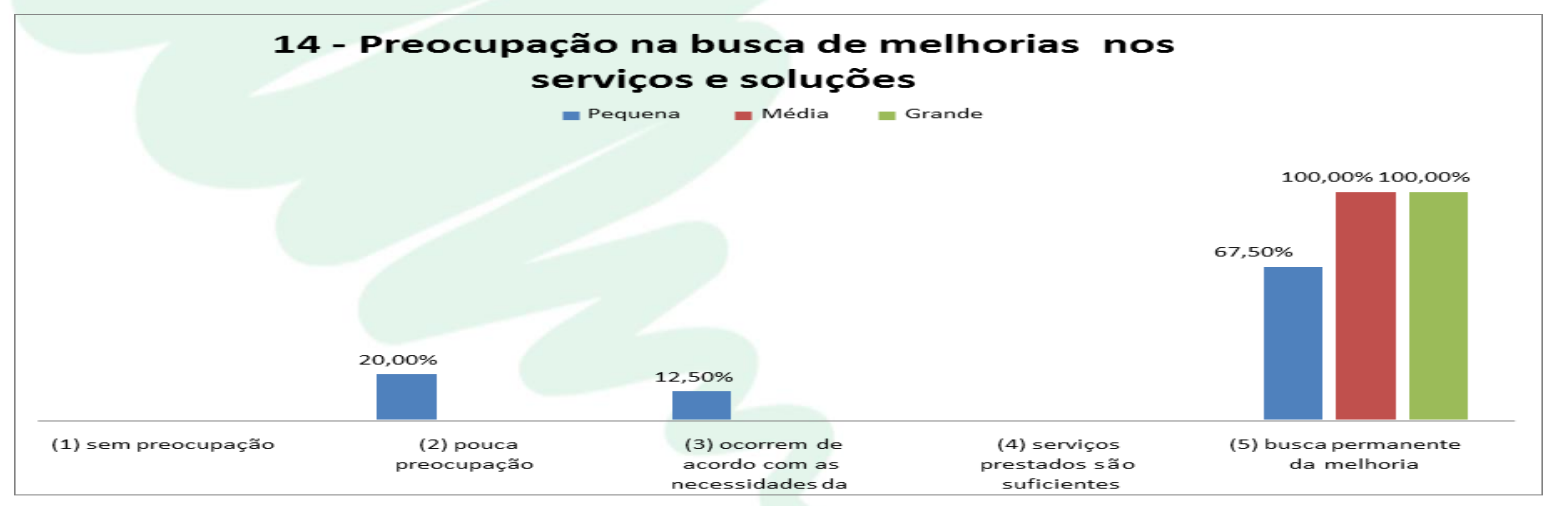

Gráfico 7 - Busca de melhorias (serviços e soluções)

Mas, sob o ponto de vista das estratégias corporativas, a melhoria de seus serviços parece estar associada à busca por uma maior eficácia operacional. Se a intenção é fazer seus modelos de negócio funcionarem a contento, então, é preciso otimizacao da eficácia operacional. Desta forma, há uma influencia positiva sobre a eficiência de seu modelo de negócio. Estas ligações parecem estar bem compreendidas pelos médios e grandes OL (Grupos 2 e 3), como mostra o Gráfico 7, ainda que não necessariamente, ou não inteiramente, pelos pequenos OLs. Aparentemente, o grau de especialidade atingido por muitos dos pequenos OLs, indica uma saturação de sua busca por melhoria.

\section{CONSIDERAÇÕES FINAIS}

Nos últimos anos, a evolução das práticas empresariais tem levado a considerar a logística, em muitos casos, como condicionante e de papel fundamental à própria estratégia corporativa. Um bom modelo de negócio, de fato, constitui uma eficaz estratégia que sustenta o sucesso empresarial. Como justificado anteriormente, o Modelo de Negócios de Bovet e Martha (2001) foi selecionado para orientar a presente pesquisa. Por questões de foco, duas das cinco dimensões do modelo (Proposta 
de Valor e Controle Estratégico), para avaliar o comportamento das principais empresas brasileiras de logística.

Conclusivamente, pode-se dizer que as empresas de logística sediadas no Brasil, têm comportamento distinto em relação aos dois parâmetros analisados. Em relação à Proposta de Valor pode-se concluir que cada grupo de empresa dá mais ênfase a diferentes elementos da proposta. Grandes empresas concentram-se na oferta de superserviços, isto é, na entrega do pacote completo de serviços. Médias empresas concentram-se na oferta de soluções de conveniência, isto é, em pacotes que contam com alguns serviços executados por seus parceiros ou com aqueles com os quais mantêm alianças estratégicas. Pequenas empresas de logística, por fim, voltam-se mais para a personalização de seus serviços.

Os indicadores que caracterizam as distintas ênfases são os seguintes.

(a) os grandes OL's concentrando sua atenção nos Super-serviços são caracterizados pela:

- Integração de seu portfólio de serviços, isto é, oferta de pacotes completos de serviços; e

- pela gestão integrada de seu portfólio, isto é, pela sincronia entre os vários serviços, de forma a aumentar a percepção de valor dos clientes.

(b) os médios OL's concentrando sua atenção em Serviços de Conveniência são caracterizados pela:

- Otimização do portfólio de serviços, isto é, por possuírem menos serviços, tentam combiná-los ao máximo para aumentar suas margens; e

- Gestão de alianças estratégicas, isto é, aumentam seus portfólios baseados em serviços que seus parceiros têm condições de oferecer e assim aumentam sua competitividade diante dos grandes OL's.

(c) os pequenos OL's concentrando sua atenção na Personalização são caracterizados pela:

- Especialização de operações logísticas, isto é, são especializados em uma ou algumas poucas formas de serviços logísticos; e

- Especialização por clientela, concentrando-se em nichos específicos de demandas por serviços logísticos.

Ainda, por focarem em elementos distintos da proposta de valor, as empresas de logística apresentam um desalinhamento intrínseco entre o parâmetro proposta de valor e controle estratégico. Seddon e Lewis (2003) defendem que um modelo de negócio é uma resultante da estratégia empresarial e que a deformidade do modelo advém das origens das combinações de capacidades e recursos e processos aparentemente desconexas com a estratégia, mas que resultam na efetividade desta. No seu conjunto, os três grupos de OL's, possuem um foco interno distinto para sustentar sua estratégia empresarial, limitada pelas propostas de valor e controle estratégico (Fig.1).

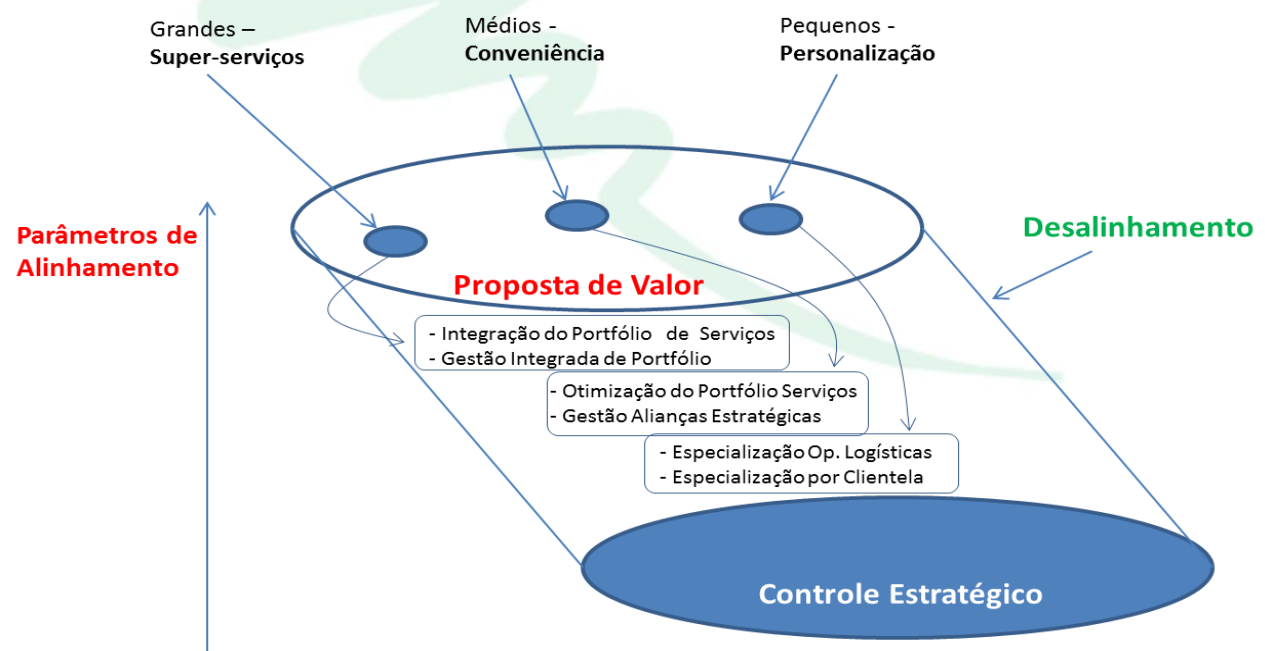

Extensão do Alinhamento

Figura 1 - Desalinhamento Intrínseco de ênfase na Proposta de Valor 
Pode-se notar que, para garantir super serviços, os grandes OL's usam a a gestão integrada de seu portfólio, enquanto que os operadores logísticos médios usam a otimização de portfólio e gestão de alianças estratégicas, como elementos de controle estratégico. Já os pequenos operadores logísticos, usam a especialização de operações logísticas e a especialização por clientela, como elementos inarredáveis para o seu controle estratégico.

O alinhamento das distintas ênfases nos modelos de negócio dos três grupos, porém, é caracterizado pela preocupação de controle de uma única variável, o seu relacionamento com os clientes. Usando a lógica de Seddon e Lewis (2003), pode-se representar o fenômeno, mostrado na Figura 2 , com comportamento diverso, sem distorsao, entre a proposta de valor e o controle estratégico.

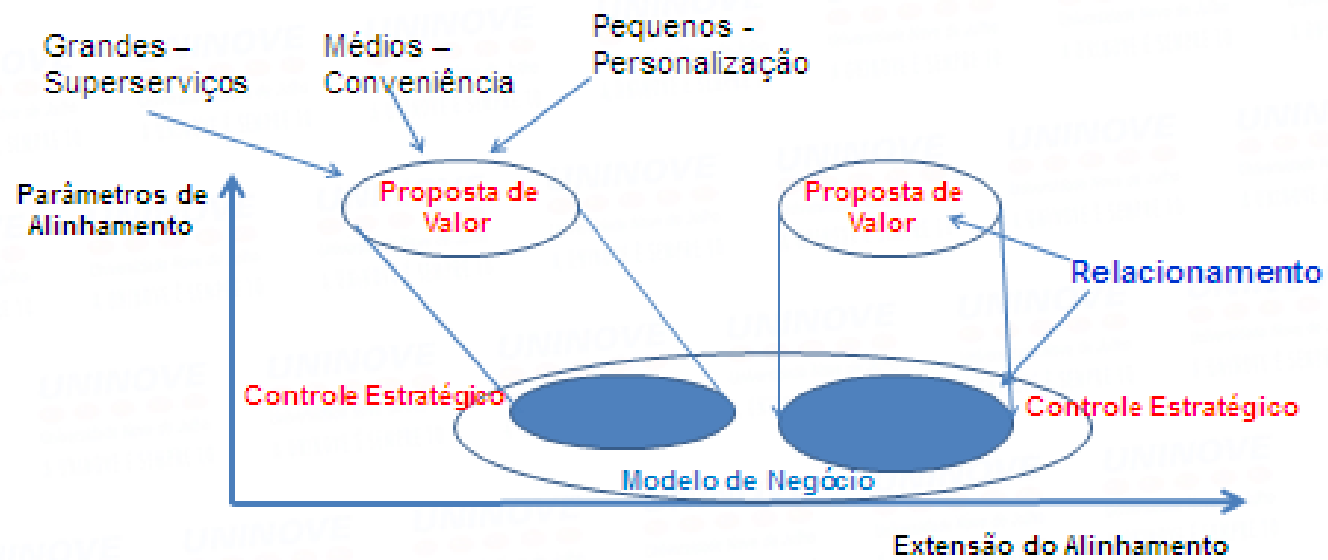

Figura 2 - Alinhamento da Ênfase entre Proposta de Valor e Controle Estratégico

Esses comportamentos levam concluir que Grandes Operadores voltam-se sistematicamente para os superserviços, isto é, para oferta de serviços e soluções integradas, os Pequenos Operadores focam essencialmente a especialização. Especializacao é distinta da personalização, mas ainda assim, carrega boa dose dessa, na medida em que o pequeno Operador Logístico especializa-se em tarefas ou serviços específicos para fidelizar clientes ou para distinguir-se como um "expert" diante do mercado de transporte, por seu serviço especializado. Para os Grandes Operadores, ao contrário, integrar um conjunto de soluções logísticas é sua forma de operar. Competem, portanto, com base em especialidade de serviços.

Quanto aos Operadores de médio porte, nitidamente voltam-se para soluções convenientes. Como seu portfólio de serviços não é ainda completo, tentam estabelecer alianças estratégicas com seus clientes, de forma a utilizar suas capacidades de recursos, já que isto é questão de sobrevivência, não de aumento da lucratividade do negócio.

O Controle Estratégico no Modelo de Bovet e Martha (2001), significa de que maneira o OL protege sua fonte de lucro por meio de vantagens competitivas sustentadoras. Sob esse aspecto, Pequenos Operadores, por focarem a especialização logística, encontram aí uma base de serviços que lhes dá garantia de domínio de seu segmento econômico.

No caso dos Operadores de Médio Porte, o controle estratégico está na gestão dos serviços de conveniência. Como não possuem ainda um portfólio de serviços completo, como os Grandes Operadores, os de Médio Porte precisam garantir, por meio de alianças estratégicas, a otimização de uso de seus recursos e capacidades. Assim, é nas alianças estratégicas que esses operadores encontram campo maior capacidade competitiva.

Os Grandes Operadores, por sua vez, acham no domínio de seu portfólio de serviços, controle estratégico. Para esses operadores o foco é oferecer um pacote integrado, amplo e completo de serviços logísticos. Quanto maior for o domínio do espectro de serviços, maior sua capacidade de competir e manter de forma sustentável seu negócio.

Com relação às limitações da pesquisa, apesar de ser quantitativa e intencionalmente representativo, é muito difícil saber-se qual o entendimento do conjunto das perguntas para os respondentes no momento em que respondiam ao questionário. Respostas específicas podem estar atreladas, ao momentum da empresa e podem não necessariamente representar seu quotidiano. 


\section{REFERÊNCIAS}

ABML - Associação Brasileira de Movimentação Logística (1999). O Conceito de Operador Logístico. Revista Tecnologística, Fev. p.35-45.

Applegate, L.M. (2000). E-Business Models: Making sense of the internet business landscape. In: Dickson, G. and DeSanctis, G. (eds.) Information Technology and the Future Enterprise. (NJ): Prentice-Hall, 49-101.

Bade, D. J., Mueller, J. K. (1999). New for the millennium: 4PL", Transportation \& Distribution, February, 78-80.

Berglund, P.; Peters, M. (2000). Third-party logistics in Europe - five years later, International Journal of Physical Distribution \& Logistics Management, v.30 (5), 425-442.

Bovet, D.; Martha, J. (2001). Value Nets - Breaking the Supply Chain to Unlock Hidden Profits. N.Y.: John Wiley \& Sons.

Christopher, M. \& Towill, D. (2001). An integrated model for the design of agile supply chains. International Journal of Physical Distribution \& Logistics Management, vol. 31(4), 235-246.

Copacino, W.C. (1998). Copacino on strategy: get the complete supply chain picture. Logistics Management and Distribution. Report 37 (11), 45.

Cottrill, K. (2000). Return to sender. Traffic World. v. 262 (7), 17-18.

Dornier, P.; Ernst, R.; Fender, Michel; \& Kouvelis, P. (2000). Logística e Operações Globais. São Paulo: Atlas.

Fleury, P. F. (2001). Vantagens Competitivas e Estratégicas no Uso de Operadores Logísticos. Artigo de Centro de Estudos em Logística COPPEAD - UFRJ.

Gomes, C. F. Ribeiro, P. C. (2004). Gestão da Cadeia de Suprimentos integrada à tecnologia da informação. São Paulo: Pioneira Thomson Learning.

Hagel III, J. (2003). Pensando Fora do Quadrado. Rio de Janeiro: Campus.
Hoffman, K.C. (2000). Just What is a 4PL Anyway? Global Logistics \& Supply Chain Strategies. Disponível em: www.supplychainbrain.com/content/index.php?id $=5032 \& \mathrm{cHash}=081010 \& \mathrm{tx}$ _ttnews $[\mathrm{tt}$ news $]=221$

4. Acesso em 01/02/2016.

Laarhoven, P., Berglund, M. Peters, M. (2000). Thirdparty logistics in Europe - five years later, International Journal of Physical Distribution \& Logistics Management, v.30 (5), 425-442.

Associação Nacional de Transporte de Carga e Logística. 2015. Disponível em: http://www.portalntc.org.br/media/images/publica coes/anuario-2011-2012/index.html\#58. Acesso em: 20/11/2015.

Porter, M. E. (1998). On Competition. Cambridge (MA): Harvard Business School Publishing.

Rodrigues, L.C. (2006). Tecendo um Nova Rede de Integração. In: Microsoft (Coord), Lucratividade pela Inovação, p. 63-103. Rio de Janeiro: Elsevier.

Santos, A. R. (2001). Metodologia Científica: a construção do conhecimento. $4^{\mathrm{a}}$ ed. Rio de Janeiro: D P\&A.

Seddon, P. B.; Lewis, G. P. (2003). Strategy and Business Models: what's the difference? Proceedings of the PACIFIC ASIA CONFERENCE ON INFORMATION SYSTEMS, 10-13 July.

Sink, H. L.; Langley, Jr., C. J.; Gibson, B. J. (1996). Buyer observations of the US third-party logistics market. International Journal of Physical Distributions \& Logistics Management v. 18 (2),163-189.

Skjoett-Larsen, T. (2000). Third party logistics - from an inter organizational point of view, International Journal of Physical Distribution And Logistics Management, v.30 (2), 112-127.

Wilson, R., Delaney, R., e Delaney R.V. (2015). Logistics and the internet: in the Frantic Search for Space, it is Still About Relationships. Report on XI Annual State of Logistics Report, National Press Club, Washington, DC, 05-06-2000. Disponível em:

http://issuu.com/publicare/docs/tecno_maio_2001_ completa? $=3094345 / 6617296 \quad$ Acesso em: $16 / 03 / 2015$. 